\title{
MONITORING CAIRAN INFUS BERDASARKAN INDIKATOR KONDISI DAN LAJU CAIRAN INFUS MENGGUNAKAN JARINGAN WIFI
}

\author{
Ruslan Agussalim ${ }^{1}$, Adnan ${ }^{2}$, Muh. Niswar ${ }^{3}$ \\ 11ruslanaguspnk@gmail.com, ${ }^{2}$ adnan.unhas1@gmail.com, ${ }^{3}$ niswar@unhas.ac.id \\ ${ }^{1}$ Pascasarjana Sistem Komputer, STMIK Handayan, ${ }^{2,3}$ Dosen Jurusan Teknik Elektro dan Teknik \\ Informatika, Universitas Hasanuddin, Makassar, Indonesia
}

\begin{abstract}
Abstrak
Sistem monitoring cairan infus sampai saat ini belum banyak ditemukan di rumah sakit ataupun institusi kesehatan lainnya tetapi sangat membantu perawat dalam melaksanakan tugas rutinnya dalam memantau kondisi cairan infuse. Makalah ini membahas tentang perancangan system monitoring yang dapat memantau kondisi cairan infus secara realtime menggunakan pc maupun smartphone. Sistem ini bekerja mengatur tetesan infuse permenit dan memberitahukan kondisi cairan infuse yang akan habis. Hasil pengujan didapatkan pengaturan tetesan infuse kurang tepat, terdapat selisih yang bervariasi di tiap pengujian sedangkan pengujian kondisi cairan infuse bekerja dengan tepat, ini dibuktikan dengan alarm pada pc dan smartphone selalu berbunyi pada saat cairan infuse akan habis.
\end{abstract}

Kata kunci: Infus, Arduino Uno, Ethernet Shield, Potensiometer

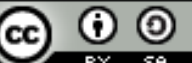

\section{Pendahuluan}

Semakin berkembangnya kemajuan teknologi, belakangan ini meningkatkan kreasi manusia dalam menciptakan perangkat yang dapat mendukung kinerja manusia dalam melakukan proses pekerjaan agar lebih praktis dan efisien. Perkembangan teknologi itu dapat memberikan manfaat bila diterapkan secara tepat. Seiring dengan hal tersebut, maka kebutuhan teknologi juga sangat dibutuhkan dalam dunia medis. Dengan kondisi rumah sakit yang luas, jumlah pasien yang banyak serta keterbatasan tenaga medis dan tuntutan pelayanan pada pasien yang baik selalu menjadi masalah dalam setiap rumah sakit. Salah satu masalahnya adalah pemberian cairan infus.

Alat infus adalah salah satu peralatan medis yang paling banyak digunakan. Dalam dunia kedokteran dan keperawatan infus merupakan alat yang paling sering digunakan, sekitar $90 \%$ pasien di rumah sakit menerima berbagai pengobatan melalui infus.

Pemberian cairan melalui infus adalah pemberian cairan yang diberikan pada pasien yang mengalami pengeluran cairan atau nutrisi yang berat. Tindakan ini membutuhkan kesterilan mengingat langsung berhubungan dengan pembuluh darah. Pemberian cairan melalui infus dengan memasukkan kedalam vena (pembuluh darah pasien) diantaranya vena lengan (vena sefalika basal ikadan median akubiti), pada tungkai (vena safena) atau vena yang ada dikepala, seperti vena temporalis frontalis (khusus untuk anak-anak).

Dalam sistem pemantauan cairan infus yang berada di rumah sakit yang sekarang, masih dilakukan secara manual oleh tenaga medis yang setiap waktu mengecek kapasitas cairan infus atau melalui keluarga pasien yang menunggu ketika cairan infus hampir habis akan memberitahu tenaga medis. Hal tersebut tentu kurang efektif selain karena sangat minimnya tenaga medis juga mengurangi hak pasien beserta keluarga untuk beristirahat karena ikut memantau.

Berdasarkan latar belakang tersebut maka dalam penelitian ini akan dirancang suatu sistem pendeteksian kondisi cairan infus yang secara realtime dimonitoring oleh perawat. Harapannya adalah dengan diterapkannya alat ini maka permasalahan yang timbul karena kelalaian petugas dapat diminimalisir

\section{Landasan Teori}

Sistem monitoring cairan infus merupakan system yang menggabungkan perangkat keras dan perangkat lunak.

\subsection{Perangkat keras}

Arduino adalah platform pembuatan prototipe elektronik yang bersifat open-source hardware yang berdasarkan pada perangkat keras dan perangkat lunak yang fleksibel dan mudah digunakan[1][2], 
penggunaan arduino dalam system ini untuk menyelaraskan seluruh perangkat keras yang digunakan dalam perancangan system monitoring cairan infuse. Motor servo adalah sebuah motor dengan sistem umpan balik tertutup di mana posisi dari motor akan diinformasikan kembali ke rangkaian kontrol yang ada di dalam motor servo [3], penggunan motor servo dalam system ini untuk mengatur dan mengendalikan tetesan infuse, membuka dan menutup laju tetesan infuse. Potensiometer adalah sebuah alat elektromekanik yang mengandung elemen tahanan yang dihubungkan oleh sebuah kontak geser yang dapat bergerak [4]. Penggunaan potensiometer dalam system ini untuk mengukur volume cairan infuse. Ethernet shield menambah kemampuan arduino board agar terhubung ke jaringan computer [5]. Penggunaan Ethernet shield dalam system ini sebagai media penghubung antara hardware yang terpasang pada infuse dengan computer maupun smartphone.

Beberapa penelitian terdahulu yang merancang system monitoring cairan infuse yaitu Yuktika dkk[6], menggunakan perangkat mikrokontroler atmega32, sensor led dan fotodioda, wireless lan,system ini bekerja dengan memantau tetesan infuse melalui sensor yang digunakan apabila terjadi macet atau penyumbatan akan memberitahu pc yang digunakan. Akhmad Zainuri dkk[7], menggunakan mikrokontroler atmel8535, sensor strain gauge,multimeter,pc, system ini bekerja mengetahui terjadi penyumbatan dengan membaca hasil yang dikeluarkan oleh multimeter. Abdy Muslim dkk[8], menggunakan mikrokontroler atmega 8535 , sensor led, radio frekuensi YS1020UB, motor servo, computer, system ini bekerja dengan membaca pergerakan tetesan infuse melalui sensol led yang terhubung dengan mikrokontroler dan melaui frekuensi radio dapat terhubung ke PC.

\subsection{Software.}

PHP adalah Bahasa server-side -scripting yang menyatu dengan HTML untuk membuat halaman web yang dinamis. Karena PHP merupakan server-side-scripting maka sintaks dan perintahperintah PHP akan diesksekusi diserver kemudian hasilnya akan dikirimkan ke browser dengan format HTML.[9]

Penggunaan php dalam system ini salah satunya dalam control infuse, berikut contoh scripnya.

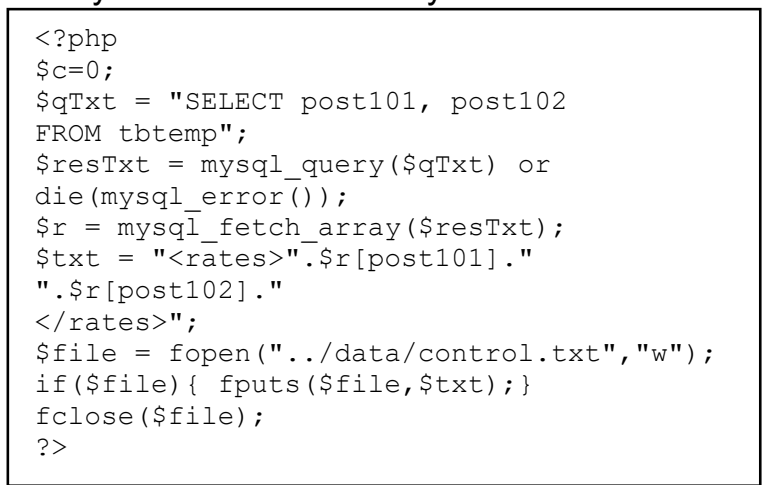

Arduino adalah bahasa pemrograman yang mirip bahasa c yang digunakan pada AVR tetapi lebih disederhanakan. Penggunaan bahasa arduino dalam perancangan system ini salah satunya dalam Library adduino. MySQL adalah salah satu jenis database server yang sangat terkenal dan banyak digunakan untuk membangun aplikasi web yang menggunakan database sebagai sumber dan pengolahan datanya [9].

\section{Arsitektur \& Perancangan Sistem}

Rancangan dari penelitian ini adalah fokus pada sistem monitoring cairan infus pada komputer dan smartphone. Perancangan penelitian ini diharapkan dapat membantu monitoring perawat dalam memantau cairan infus pada pasien, sehingga dapat mencegah terjadinya kehabisan cairan infus, penyumbatan cairan infus pada pasien dan emboli paru.

Dalam tahapan perancangan ini mengutamakan bagaimana sebuah sistem dapat memantau volume infus secara real time melalui komputer dan smartphone yang ada pada perawat. Pada perancangan penelitian ini terdapat arsitektur sistem yang saling terhubung yaitu input, proses dan output. Input dari sistem ini adalah data pasien dan faktor tetes yang diberikan pada pasien, data pasien tersimpan pada database sebagai informasi pengguna infus sedangkan faktor tetes digunakan untuk memberikan berapa tetes permenit pasien akan menerima cairan infus. Faktor tetes ini di kendalikan oleh motorservo. Proses dari sistem ini menggunakan arduino uno ATMega328 sedangkan output dari sistem ini adalah bagaimana sistem dapat memberikan informasi volume infus pada computer dan smartphone. 


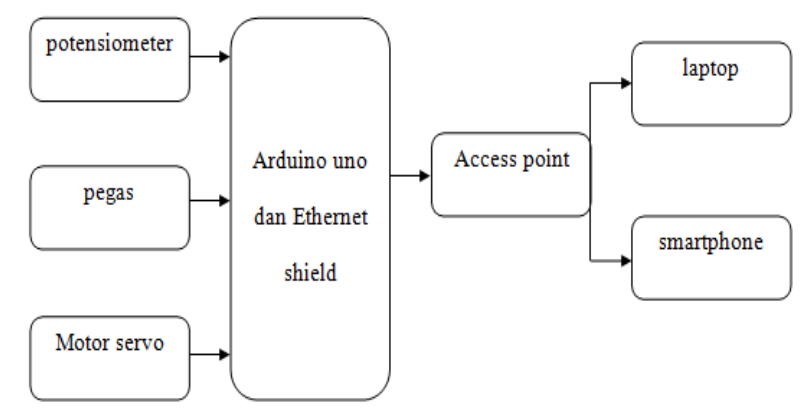

Gambar 1. Diagram Blok

Berdasarkan diagram blok diatas berikut adalah flowchart untuk monitoring cairan infus.

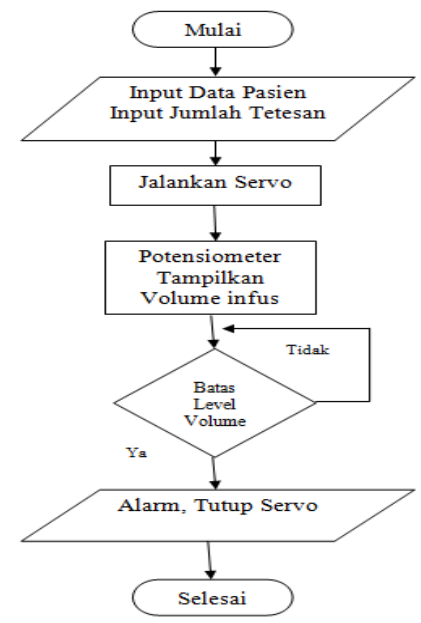

Gambar 2. Flowchart monitoring cairan infus.

Dari flowchart diatas kegiatan pertama kali yang dilakukan system adalah penginputan data pasien dan jumlah tetesan yang akan diberikan ke pasien. Data pasien tersimpan pada database dengan table tbpasien sedangkan jumlah tetesan tersimpan pada table tbtemp.

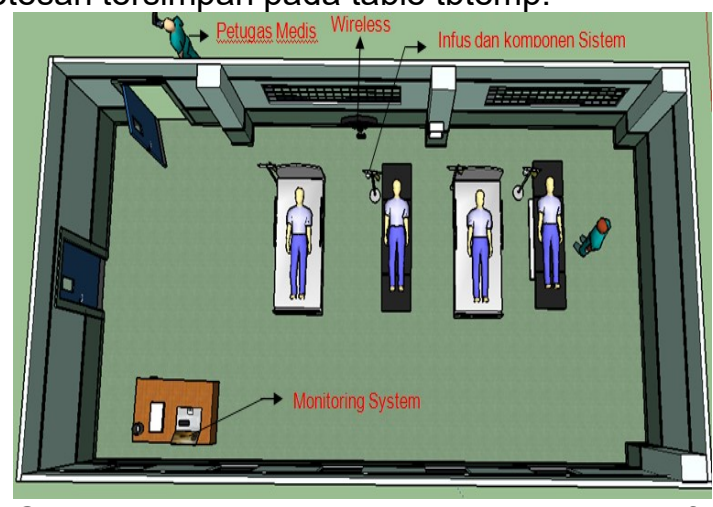

Gambar 3. Rancangan sistem Monitoring Infs

\section{Hasil dan Pengujian Sistem}

\subsection{Hasil Penelitian}

Hasil rancangan system monitoring cairan infus terdiri dari beberapa rangkaian perangkat keras, dan rangkaian perangkat lunak, rangkaian perangkat keras terdiri dari : rangkaian mekanik, arduino uno, ethernet shield, wireless access point, sensor potensiometer, sedangkan rangkaian perangkat lunak 
terdiri dari aplikasi monitoring cairan infus. Gambar system monitoring cairan infus berdasarkan indicator kondisi dan laju tetesan infus menggunakan jaringan wifi dapat dilihat pada gambar di bawah.

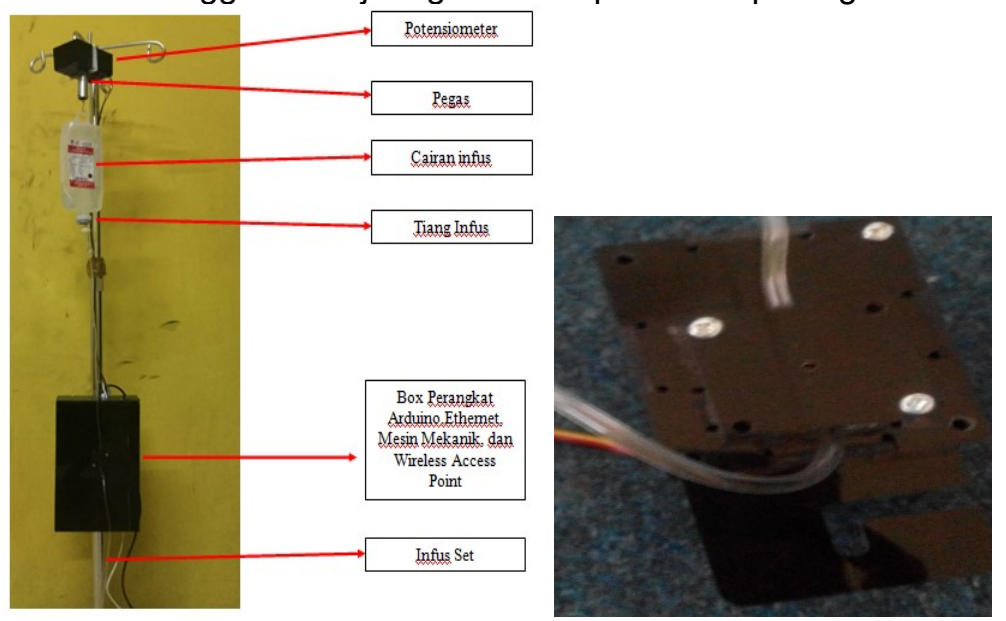

Gambar 4. Hasil Perancangan Sistem Gambar 5. Mesin mekanik

a. Rangkaian Perangkat Keras Mesin mekanik

Pada bagian ini terdapat mekanik yang menggantikan fungsi dari klem infus. Terdiri dari dua bagian yaitu bagian penggerak penjepit selang infus dan bagian penjepit selang infus. Bagian penggerak penjepit selang infuse ini terdiri dari motor servo dan gearbox yang telah dimodifikasi agar dapat bergerak mengatur laju tetesan infuse

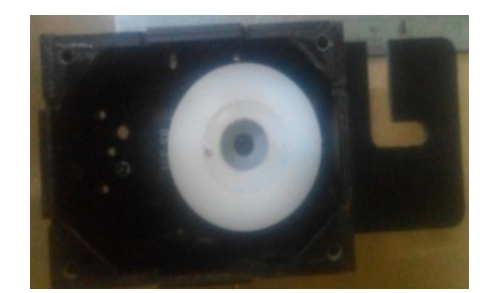

Gambar 6. Motor servo dan gearbox

Motor servo bekerja menggunakan derajat 0 sampai dengan 90 derajat, dan dikondisikan dengan faktor tetes infus, berikut table derajat motor servo yang telah dikodisikan dengan factor tetes infus.

\begin{tabular}{ccc}
\multicolumn{3}{c}{ Tabel 1. Pengaturan Faktor Tetes Infus } \\
\hline No & $\begin{array}{c}\text { Derajat } \\
\text { Servo }\end{array}$ & Faktor Tetes Permenit \\
\hline 1 & 90 & 0 (Tidak menetes) \\
2 & 52 & 20 \\
3 & 50 & 30 \\
4 & 49 & 60 \\
5 & 0 & Lancar( Tetesan tidak \\
& & terhitung) \\
\hline
\end{tabular}

b. Ulir pada mesin mekanik dan Wireless Access point

Pada bagian penjepit selang infus digunakan ulir yang bergerak untuk menutup selang infus, ulir dapat bergerak naik untuk menutup selang infus dan bergerak turun untuk membuka selang infus.

Agar arduino dapat menerima data inputan dari system, dan memberikan output ke system maka dibutuhkan Access point. Access point yang digunakan adalah TpLink TL MR3040, alasan menggunakan alat ini karena ukuran alat kecil dan dapat digunakan sebagai router portable. 


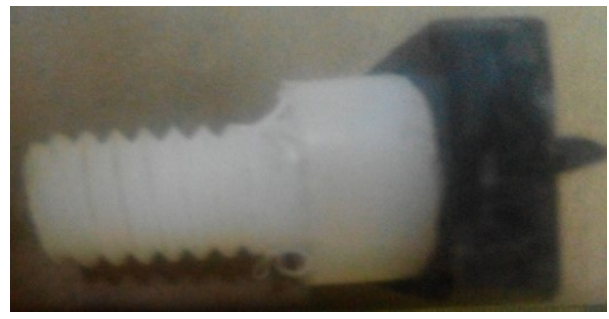

Gambar 7. Ulir pada mesin mekanik

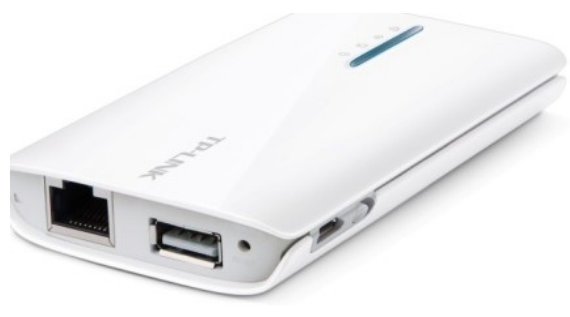

Gambar 8. Wireless access point

c. Arduino Uno, Ethernet Shield dan Sensor Potensiometer

Arduino adalah pengendali mikro single-board yang bersifat open-source yang dirancang untuk memudahkan penggunaan elektronik dalam berbagai bidang. Hardwarenya memiliki prosesor Atmel AVR, softwarenya memiliki bahasa pemrograman sendiri. Penggunaan arduino uno dalam system sebagai penghubung antara perangkat keras dengan perangkat lunak dalam system nonitoring cairan infus, dan untuk dapat terhubung dengan computer maka dibutuhkan media Ethernet shield.

Sensor pendeteksi tetesan cairan infus yang digunakan yaitu potensiometer. Kapasitas resistensi pada ptensiometer yaitu $10 \mathrm{k} \Omega$, namun dalam implementasi system hanya digunakan $8 \mathrm{k} \Omega$. Untuk dapat menghasilkan output berupa volume infus maka potensiometer di rangkai dengan pegas. Fungsi pegas akan mendorong keatas resistensi potensiometer jika volume berkurang.

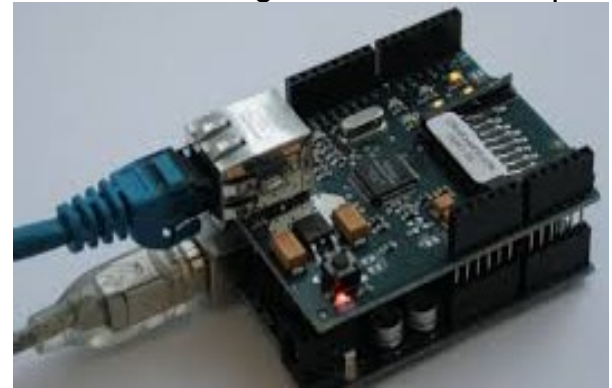

Gambar 9. Arduino dan Ethernet shield

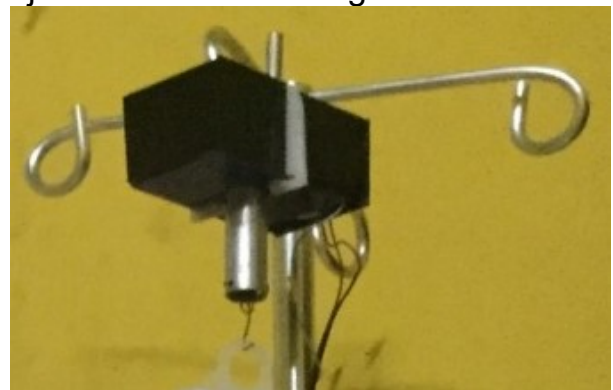

Gambar 10. Sensor potensiometer

d. Rangkaian Perangkat Lunak

1) Perangkat lunak Arduino Uno

Pada perangkat lunak arduino.ino inisialisasi seluruh hardware yang digunakan pada system monitoring cairan infus, isi dari perangkat lunak arduino.ino adalah penggunaan alamat ip untuk Ethernet shield, alamat ip untuk server dan alamat ip untuk access point. Selanjutnya pembacaan port pada arduino pada pin 3 port digital digunakan untuk pembacaan servo. Pada pin 10,11,12, dan 13 port digital digunakan untuk pembacaan Ethernet shield sedangkan pada pin a0 dan a1 port analog digunakan untuk pembacaan potensiometer

2) Perangkat lunak system monitoring cairan infus mysql.

Sistem monitoring cairan infus menggunakan bahasa pemrograman php, dan database

\subsection{Pengujian Sistem}

Pada pengujian sistem penelitian ini terbagi manjadi dua bagian, yaitu pengujian perangkat keras dan pengujian perangkat lunak.

a. Pengujian Perangkat Keras

Perangkat keras yang di uji adalah Potensiometer, dengan mengukur resistensi pada potensiometer akan didapatkan tegangan keluar (Vout), dan apabila pengukuran resistensi naik atau turun menunjukkan bahwa potensiometer sudah bekerja. Cara pengujian yaitu menjalankan system dengan posisi servo 0 derajat, akan diukur resistansi volume infus mulai $500 \mathrm{ml}$ sampai dengan volume infus habis. Hasil pengujian ditampilkan pada tabel dan grafik berikut: 
ILKOM Jurnal Ilmiah Volume 8 Nomor 3 (Desember 2016)

ISSN: 2087-1716

Tabel 2. Uji Vout berdasarkan volume infus

\begin{tabular}{|c|c|c|c|c|}
\hline No. & $\begin{array}{r}\text { Waktu } \\
(\mathrm{m})\end{array}$ & $\begin{array}{l}\text { Volume } \\
\text { Infus (ml) }\end{array}$ & $\begin{array}{c}\text { Resisto } \\
(\mathrm{O})\end{array}$ & $\begin{array}{l}\text { Vout } \\
\text { (v) }\end{array}$ \\
\hline 1 & 1 & 500 & $\begin{array}{c}R 2=0 \\
R 1=10\end{array}$ & 0 \\
\hline 2 & 2.23 & 450 & $\begin{array}{l}\mathrm{R} 2=1.75 \\
\mathrm{R} 1=8,25\end{array}$ & 0.88 \\
\hline 3 & 2.43 & 400 & $\begin{array}{l}\mathrm{R} 2=2.06 \\
\mathrm{R} 1=7,94\end{array}$ & 1.03 \\
\hline 4 & 2.52 & 350 & $\begin{array}{l}\mathrm{R} 2=2,41 \\
\mathrm{R} 1=7,59\end{array}$ & 1.21 \\
\hline 5 & 3 & 300 & $\begin{array}{l}\mathrm{R} 2=2,64 \\
\mathrm{R} 1=7,36\end{array}$ & 1.32 \\
\hline 6 & 3,04 & 250 & $\begin{array}{l}\mathrm{R} 2=3,33 \\
\mathrm{R} 1=6,67\end{array}$ & 1.65 \\
\hline 7 & 3,09 & 200 & $\begin{array}{l}\mathrm{R} 2=3,50 \\
\mathrm{R} 1=6,50\end{array}$ & 1.75 \\
\hline 8 & 3,18 & 150 & $\begin{array}{l}\mathrm{R} 2=3,78 \\
\mathrm{R} 1=6,22\end{array}$ & 1.89 \\
\hline 9 & 3,31 & 100 & $\begin{array}{l}\mathrm{R} 2=3,89 \\
\mathrm{R} 1=6,11\end{array}$ & 1.95 \\
\hline 10 & 3.54 & 50 & $\begin{array}{l}R 2=4,50 \\
R 1=5,50\end{array}$ & 2.25 \\
\hline 11 & 4,34 & 0 & $\begin{array}{l}\mathrm{R} 2=5,70 \\
\mathrm{R} 1=4,30\end{array}$ & 2.85 \\
\hline
\end{tabular}

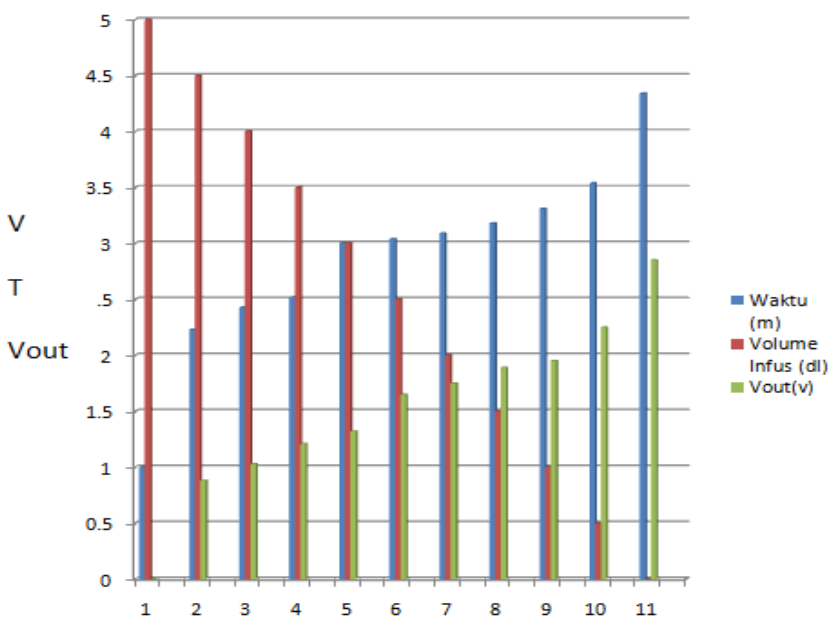

Gambar 11. Grafik pengukuran Vout berdasarkan volume infus

Dari hasil pengujian perangkat keras, didapatkan Vout berbanding terbalik dengan volume infus dan searah dengan waktu, hasi pengujian ini menunjukkan bahwa potensiometer sudah bekerja, sehingga dapat menampilkan volume infus pada system monitoring cairan infus.

\section{b. Pengujian Perangkat Lunak}

Perangkat lunak yang diuji adalah system monitoring dengan melukan pengontrolan pada servo, agar servo dapat menjalankan tetesan infus dan menutup tetesan infus.

Hasil pengujian Tetesan Infus dan Volume Infus dengan posisi servo 49 derajat ditampilkan dalam table dan grafik : 
ILKOM Jurnal Ilmiah Volume 8 Nomor 3 (Desember 2016)

ISSN: 2087-1716

Tabel 3. Pengujian Tetesan Infus dan Volume Infus

\begin{tabular}{|c|c|c|c|c|}
\hline No. & Waktu (m) & Tetes / menit & $\begin{array}{c}\text { Volume Infus } \\
\text { Pada Aplikasi (mI) }\end{array}$ & $\begin{array}{c}\text { Volume Infus Res } \\
(\mathrm{grm} / \mathrm{m})\end{array}$ \\
\hline \multicolumn{5}{|c|}{ Hasil Uji Pertama } \\
\hline 1 & 0 & 0 & 500 & 500 \\
\hline 2 & 1 & 63 & 498 & 500 \\
\hline 3 & 5 & 49 & 495 & 499 \\
\hline 4 & 10 & 46 & 491 & 497 \\
\hline 5 & 15 & $\overline{42}$ & 489 & 495 \\
\hline 6 & 20 & 40 & 487 & 493 \\
\hline 7 & 25 & 40 & 485 & 491 \\
\hline 8 & 30 & 40 & 483 & 489 \\
\hline 9 & 35 & 40 & 481 & 487 \\
\hline 10 & 40 & 40 & 479 & 485 \\
\hline \multicolumn{5}{|c|}{ Hasil Uji Kedua } \\
\hline 1 & 0 & 0 & 500 & 500 \\
\hline 2 & 1 & 59 & 499 & 500 \\
\hline 8 & 5 & 50 & 497 & 500 \\
\hline 4 & 10 & 45 & 495 & 499 \\
\hline 5 & 15 & 41 & 494 & 498 \\
\hline 6 & 20 & 38 & 493 & 498 \\
\hline 7 & 25 & 36 & 491 & 497 \\
\hline 8 & 30 & 35 & 490 & 497 \\
\hline 9 & 35 & 35 & 489 & 496 \\
\hline 10 & 40 & 35 & 488 & 495 \\
\hline \multicolumn{5}{|c|}{ Hasil Uji Ketiga } \\
\hline 1 & 0 & 0 & 500 & 500 \\
\hline 2 & 1 & 51 & 500 & 500 \\
\hline 8 & 5 & 48 & 498 & 500 \\
\hline 4 & 10 & 46 & 498 & 500 \\
\hline 5 & 15 & 44 & 497 & 500 \\
\hline 6 & 20 & 41 & 495 & 499 \\
\hline 7 & 25 & 38 & 493 & 499 \\
\hline 8 & 30 & 36 & 493 & 498 \\
\hline 9 & 35 & 34 & 490 & 498 \\
\hline 10 & 40 & 34 & 490 & 497 \\
\hline
\end{tabular}

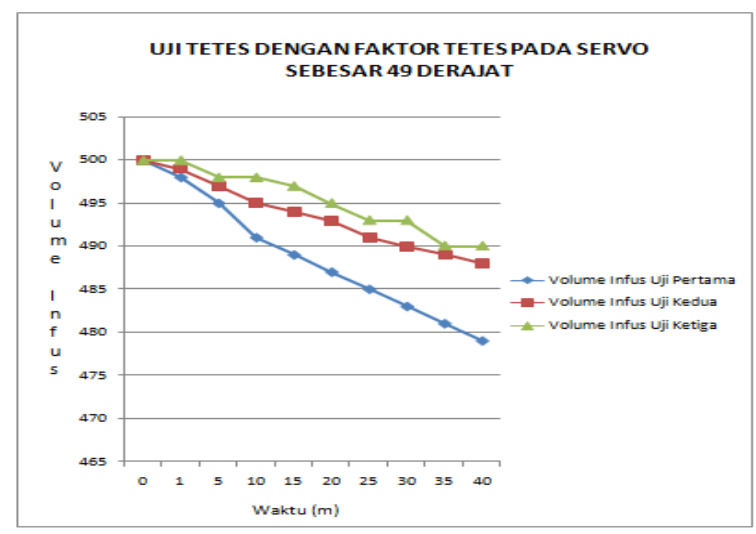

(12)

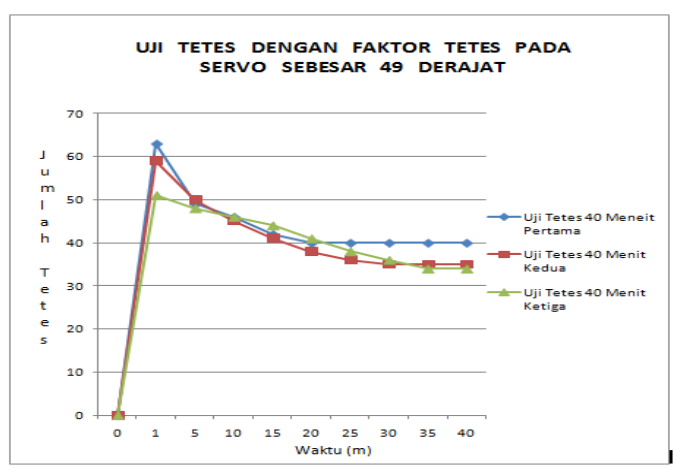

(13)

Gambar 12. Grafik hasil pengujian mengukur volume tetes dalam satuan waktu Gambar 13. Grafik hasil pengujian mengukur jumlah infus dalam satuan waktu

Dari hasil pengujian perangkat lunak, didapatkan derajat servo 49 tidak dapat membuat factor tetes infus stabil, sehingga pada tiga kali pengujian factor tetes dari menit pertama sampai menit ke empat puluh tetesan infus terus berkurang.

Begitupun dengan volume infuse hasil pengujian menunjukkan perbedaan sekitar 6 sampai dengan $7 \mathrm{ml}$ perbedaan antara volume infus pada monitor dengan volume infus real menggunakan pengukuran timbangan digital. 


\section{Kesimpulan dan Saran \\ 5.1 Kesimpulan}

Dari rancangan system monitoring cairan infus berdasarkan indicator kondisi dan laju tetesan infus menggunakan jaringan wifi yang dibuat dapat disimpulkan:

1. Monitoring cairan infus dapat dilakukan dengan merekayasa beberapa fungsi alat yaitu motor servo sebagai pengatur tetesan infus, arduino uno sebagai media komunikasi antar computer dan alat lainya, Ethernet shield sebagai penghubung arduino dengan wifi, potensiometer sebagai sensor ukur volume infus.

2. Hasil dari system monitoring dan kontroling cairan infus dapat memantau kondisi infus melalui computer dan smartphone secara realtime.

3. Motor servo untuk mengatur tetesan infus digunakan sebagai pengganti clem infus sehingga memudahkan petugas medis dalam mengontrol tetesan dan membuka serta menutup selang infus dari halaman web, namun dalam uji coba servo pada derajad 49 didapatkan factor tetes yang tidak tetap, bahkan cenderung menurun dari menit pertama sampai menit keempat puluh ini disebabkan adanya getaran pada servo yang terus bekerja sehingga posisi ulir terus berubah sehingga tidak dapat menentukan posisi yang tepat untuk menentukan factor tetes. Pengukuran volume infuse juga dalam uji coba menunjukkan selisih berat sekitar $6 \mathrm{ml}$ sampai $7 \mathrm{ml}$ antara volume infuse pada monitor dengan volume infuse real menggunakan timbangan digital.

4. Penggunaan potensiometer sebagai sensor pengukur volume infus dapat bekerja dengan baik, namun pegas yang membantu potensiometer perlu dipantau secara berkala.

\subsection{Saran}

Saran yang diberikan untuk pengembangan selanjutnya adalah:

1. Penggunaan pegas yang tepat pada sensor potensiometer untuk mengukur volume infus.

2. Analisa penyebab ketidaktepatan servo dalam menentukan factor tetes sehingga factor tetes dari menit pertama ke menit selanjutnya semakin menurun.

3. Penambahan variabel monitoring penyumbatan pada cairan infus, dengan memantau berat cairan infus secara realtime menggunakan sensor tetesan. Sehingga dapat menghindari kejadian darah pasien naik pada selang infus dan oksigen pada infus masuk kedalam tubuh.

4. Monitoring dapat dikembangkan dengan fungsi pantauan denyut jantung, pantauan nadi, dan pantauan oksigen yang dimasukkan ke dalam tubuh pasien

\section{Daftar Pustaka}

[1] Dian Artanto,"Interaksi Arduino dan labVIEW". Elex Media Komputindo.Jakarta.2012.Hal.1

[2] Ardika Wicaksana, dkk, 2014, "Membangun Sistem Keamanan Pintu Menggunakan RFID Dan Arduino Severino", STMIK Amikom, Yogyakarta.

[3] Rois, dkk, 2012, "Pengaturan Posisi Motor Servo DC Dengan Metode Fuzzy Logic", Institut Teknologi Sepuluh Nopember, Surabaya.

[4] Iwan Setiawan, 2009,"Buku Ajar Sensor dan Transducer", Fakultas Teknik universitas Diponegoro.

[5] Rois, dkk, 2012, "Pengaturan Posisi Motor Servo DC Dengan Metode Fuzzy Logic", Institut Teknologi Sepuluh Nopember, Surabaya.

[6] Yuktika, dkk, "Perancangan dan Realisasi Pendeteksian Kelancaran Aliran dan Volume Cairan Infus Berbasis Wifi", Jurnal, Fakultas Elektro dan Komunikasi Institut Teknologi Telkom

[7] Akhmad Zainuri, dkk, 2012, "Monitoring dan Identifikasi Gangguan Infus Menggunakan Mikrokontroler AVR", Jurnal EECCIS Vol. 6 No. 1 Juni 2012.

[8] Abdy Muslim, dkk, "Monitoring Cairan Infus Menggunakan Modul Radio Frekuensi YS 1020 UB Dengan Frekuensi 433 Mhz", Jurnal Teknik Elektro Fakultas Teknik Universitas Diponegoro

[9] Arief, M.Rudianto. 2011, "Pemrograman Web Dinamis Menggunakan Php dan Mysql"' Yogyakarta: ANDI. 